\title{
GEOPOLYMERS WITH CARBON OR BASALT GRIDS AND INCORPORATED MGO NANOPARTICLES FOR SHIELDING ELECTROMAGNETIC RADIATION
}

\author{
${ }^{1}$ Lucie SVOBODOVÁ, ${ }^{1}$ Totka BAKALOVA, ${ }^{2}$ Veronika TUNÁKOVÁ, ${ }^{1}$ Hiep LE CHI, \\ ${ }^{1}$ Martina RYVOLOVA, ${ }^{1}$ Anna KAVÁNOVÁ, Lukáš VOLESKÝ \\ ${ }^{1}$ Department of Material Science, Faculty of Mechanical Engineering, Technical University of Liberec, \\ Liberec, Czech Republic, EU, \\ lucie.svobodova@tul.cz, totka.bakalova@tul.cz, lechihieptul09@gmail.com, martina.ryvolova@tul.cz, \\ anna.kavanova@tul.cz, lukas.volesky@tul.cz \\ ${ }^{2}$ Department of Material Engineering, Faculty of Textile Engineering, Technical University of Liberec, \\ Liberec, Czech Republic, EU, veronika.tunakova@tul.cz
}

https://doi.org/10.37904/nanocon.2019.8548

\begin{abstract}
The development of electronic technologies and the requirement for high-speed electronic systems and devices have led to an increased improvement in the performance of electronic and telecommunication devices (mobile phones, wireless or navigation systems etc.). Long-term exposure to electromagnetic (EM) fields poses serious risks to human health (EM pollution). EM shielding materials like traditionally-used metals need to be replaced with lighter materials, which also achieve the sufficient mechanical strength and resistance.

This work deals with the topical problem of developing non-metal composites (geopolymer composites) with the aim to increase their EM shielding capabilities. Geopolymer composites consist of carbon or basalt fiber grids (size $16 \times 12 ; 22 \times 22$ or $34 \times 34 \mathrm{~mm}$ ) and nanoparticles of $\mathrm{MgO}$ (concentration $0.0 ; 5.0 ; 7.5$ or $10 \%$ ) incorporated into the matrix. Carbon (CF) and basalt fibers (BF) from roving were soaked in various different solutions (distilled water, calcium hydroxide, sodium water glass, and potassium water glass) for two weeks, six weeks and three months, and their tensile strength was examined.

The shielding efficiency (SE) of sheet materials (with different fillers) was evaluated in the $30 \mathrm{MHz}-1.5 \mathrm{GHz}$ frequency range. The electromagnetic SE was $5 \mathrm{~dB}$ for the pure geopolymer material (without any modification) and reached up to $32 \mathrm{~dB}$ for the geopolymer material with CF grids. Moreover, the modified composite material achieved different SE for altered frequencies. The results reveal the possibility to use the composite geopolymer material in the production of shielding coatings with lower costs and with environmental considerations.
\end{abstract}

Keywords: Electromagnetic shielding efficiency, geopolymer composite material, carbon fiber, basalt fiber, $\mathrm{MgO}$ nanoparticles.

\section{INTRODUCTION}

The importance of electromagnetic (EM) pollution is increasing as a consequence of increased levels of emitted electromagnetic radiation [1]. Long-term exposure to EM fields represents a considerable risk to human health [2]. Electromagnetic shielding (EMS) means the blocking of EM radiation. A decrease in EM waves involves the absorption and/or reflection of the incident radiation. [3] The shielding effectiveness (SE) is a widely used parameter expressed in decibels $(\mathrm{dB})$. A wave reduction of $30 \mathrm{~dB}$ is considered adequate for most industrial and consumer applications; $40 \mathrm{~dB}$ are required for making electronic housing and for electronic appliances; values higher than $100 \mathrm{~dB}$ imply that the material is essentially impenetrable. [1].

Materials that can be used for EM shielding include steel, copper, aluminum, and nickel; however, they are heavy and mostly corrosive. Cement-based composites such as geopolymers notably with modified properties 
can be used to absorb electromagnetic waves (EMW) [4]. Geopolymers are alumina-silica based binder materials (green concrete), which consume small amount of energy and release small amounts of carbon dioxide during production. The starting materials for geopolymer production are waste or recycled byproducts (metakaolin, fly ash, glass waste etc.). [5] Geopolymers offer excellent mechanical and thermal properties, high durability, chemical stability, corrosion resistance, low density, low permeability, and freeze-thaw resistance. However, they still have a disadvantage of being brittle similar to conventional Portland cement. Therefore, reinforcing materials are usually added to the geopolymer matrix to enhance its toughness and other specific properties like shielding efficiency against EM waves. [6]

The reinforcing materials can be either particles or fibers. The fibers are advantageous for civil engineering applications regarding cost-effectiveness, and ease of handling and production [7]. There has been much research about geopolymer composites reinforced with cotton fiber, polyvinyl alcohol, polyvinyl chloride, polypropylene, CF or BF [8]. The fibers can improve the mechanical properties of geopolymer composites $[9,10]$, such as compressive strength, flexural strength, and toughness (with an appropriate concentration) $[6,11]$. They can also be effective as an EM radiation absorber that renders them an effective shielding tool.

The mutual use of CFs or BFs with metal particles (e.g., nickel, copper, steel, $\mathrm{Fe}_{3} \mathrm{O}_{4}$ ) [2-4] in the same composite is also effective due to the electrical conductivity and magnetic character of metals. Magnesium oxide $(\mathrm{MgO})$ is physically and chemically stable at high temperatures, and it has high thermal conductivity and low electrical conductivity. $\mathrm{MgO}$ is fire resistant, termite resistant, moisture resistant, mold and mildew resistant, and is strong, which is useful especially for construction materials.

In this paper, we prepared geopolymer composites consisting of $\mathrm{CF}$ or $\mathrm{BF}$ grids and the nanoparticles of $\mathrm{MgO}$ incorporated into the matrix as an effective material for shielding electromagnetic radiation.

\section{MATERIALS AND METHODS}

\subsection{Description of the used fibers and their preparation into solutions}

The first part of the experiment describes the change of the mechanical properties of basalt and carbon rovings due to the long-term effect of chemical substances. Carbon and basalt rovings are the material basis to produce geo-meshes, which are known as grids. Grids are used as a reinforcement for technical purposes, especially in construction. In this research, carbon and basalt grids were used as a reinforcement in geopolymers of composite materials. Table 1 summarizes the specifications of the rovings used.

Table 1 Specification of the rovings used

\begin{tabular}{llcccc}
\hline & Producer & $\begin{array}{c}\text { Filament } \\
\text { diameter }[\mu \mathrm{m}]\end{array}$ & Fineness (tex) & Density [g/cm ${ }^{3}$ ] & E-Module [GPa] \\
\hline CF & Toho Tenax Co., Ltd. & 7 & 3200 & 1.77 & 250 \\
BF & DBF GmbH & 13 & 2400 & $2.6-2.8$ & 84 \\
\hline
\end{tabular}

The CFs and BFs of the rovings were prepared to a length of $50 \mathrm{~cm}$ and were divided into groups of five samples and a reference (to compare the differences). The experiment was carried out in the following steps: (1) Preparation of chemical solutions and immersion of the rovings into solutions for two weeks, six weeks and three months. The following solutions were prepared: distilled water $(\mathrm{DW})$, calcium hydroxide $\mathrm{Ca}(\mathrm{OH})_{2}$, sodium water glass $\mathrm{Na}_{2} \mathrm{SiO}_{3}\left(\mathrm{WGNa}\right.$ ) and potassium water glass $\mathrm{K}_{2} \mathrm{SiO}_{3}(\mathrm{WGK})$. The prepared solutions were poured into closable containers, into which the BFs and CFs from the rovings were added. (2) After two weeks, six weeks and three months the samples were removed from the solutions, washed thoroughly with distilled water, immersed in distilled water $(1.5 \mathrm{~h})$, and dried in an oven at $105^{\circ} \mathrm{C}$ for $24 \mathrm{~h}$. 


\subsection{Experimental evaluation of mechanical properties of fibers after 2,6 weeks and 3 months}

The experiment continued with the preparation of samples for tensile tests, which were based on the standards ASTM C1557, ASTM D3822 and ASTM D4018. The individual rovings were glued into a paper frame with dimensions $200 \times 70 \mathrm{~mm}$, with hole size $100 \times 50 \mathrm{~mm}$, and the rovings were stretched through a hole. In total there were 30 groups of rovings, each group containing ten samples for the tensile tests.

The tensile tests were performed on a TESTOMETRIC instrument. The clamping length was set to $100 \mathrm{~mm}$ and the fiber stretching speed was $10 \mathrm{~mm} / \mathrm{min}$. The instrument evaluates the highest values of strength, Young's modulus and work and fiber elongation upon breaking. Part of the experiment included the creation of a graphical record of the course of each test.

\subsection{Method of preparation of the geopolymer mixtures}

Samples of the geopolymer material, into which the CF and BF grids were built, were prepared for evaluation of the electromagnetic radiation (see Figure 1).
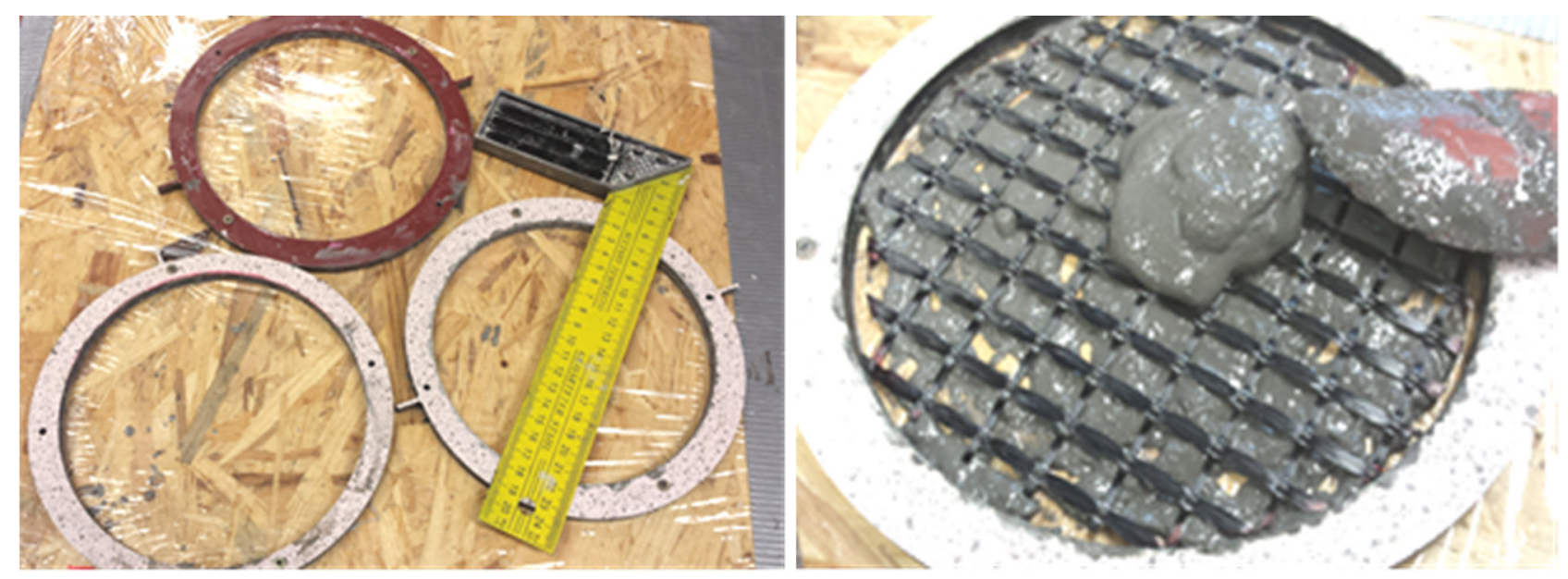

Figure 1 Preparation of forms (left) and samples (right) for evaluation of electromagnetic radiation

The following amounts of materials was used to prepare a single sample measuring $\varnothing 150 \mathrm{~mm} \times 5 \mathrm{~mm}: 50 \mathrm{~g}$ of Baucis cement, $45 \mathrm{~g}$ of an activator, $3.75 \mathrm{~g}$ of silica fume $\mathrm{SiO}_{2}, 9 \mathrm{~g}$ of $\mathrm{BFs}$ (as a filling for the geopolymer composites), $50 \mathrm{~g}$ of silica sand (labelled ST $03 / 08$ ) and $0.75 \mathrm{~g}$ of an aluminum powder. The total weight of the samples was $158.5 \mathrm{~g}$.

The test samples were prepared by adding carbon and basalt networks to the geopolymer matrixes with grid sizes of $16 \times 12 ; 22 \times 22$ and $34 \times 34 \mathrm{~mm}$. For the other samples, a geopolymer matrix with a grid size of $16 \times 12 \mathrm{~mm}$ was prepared, and MgO nanoparticles with concentrations of $0.0 ; 5.0 ; 7.5$ or $10.0 \%$ were added.

\subsection{Method of evaluation of the EMS of the composite materials}

The shielding efficiency (SE) of the prepared samples was evaluated according to ASTM standard 4935-10, which is intended for the evaluation of sheet materials. This standard works with the assumption of the impact of a plane wave on a shielding partition in the near zone of the electromagnetic field for a frequency of $30 \mathrm{MHz}$ to $1.5 \mathrm{GHz}$. The measuring fixture consists of a coaxial specimen holder (manufactured by Electro-Metrics, Inc., model EM-2107A), whose input and output are connected to a perimeter analyzer. A Rhode \& Schwarz ZNC3 circuit analyzer is used to generate and receive electromagnetic signals. 


\section{RESULTS}

\subsection{Influence of the prepared solutions on fiber resistance after 2, 6 weeks and 3 months}

Figure 2 shows BFs from a roving in the original state (Figure 2, left) and after six weeks in sodium water glass (WGNa) $\mathrm{Na}_{2} \mathrm{SiO}_{3}$ (Figure 2, centered) and potassium water glass (WGK) $\mathrm{K}_{2} \mathrm{SiO}_{3}$ (Figure 2, right), by SEM.
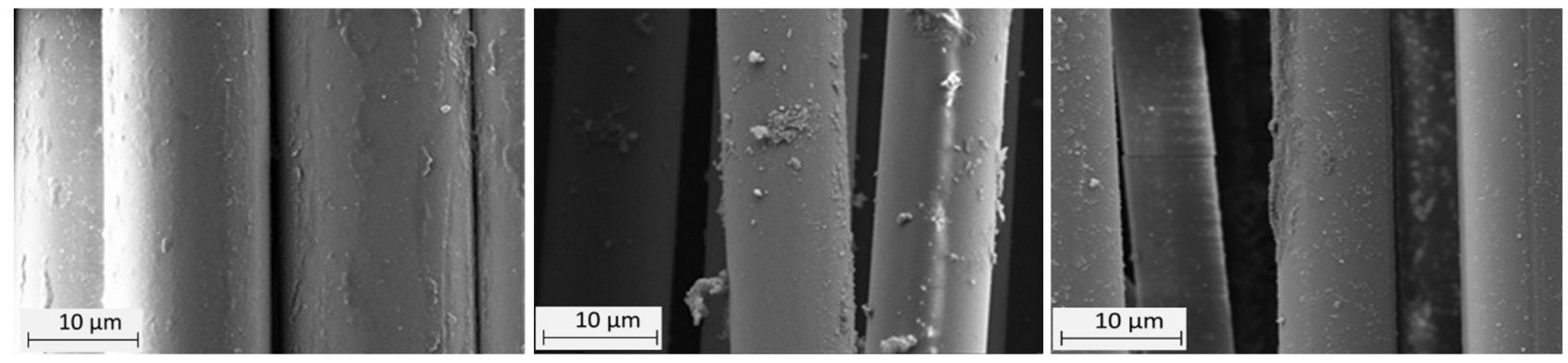

Figure 2 The original state of BFs (left), after six weeks in sodium water glass (WGNa) $\mathrm{Na}_{2} \mathrm{SiO}_{3}$ (center) and potassium water glass (WGK) $\mathrm{K}_{2} \mathrm{SiO}_{3}$ (right)

The thinning of the BFs due to the sodium and potassium water glass is very evident in the figure. Unlike BFs, after six weeks of the experiment, no change in the diameter was observed for the CFs (images not shown). The observed tiny particles on the surface of the fibers that were immersed in the different types of water glass (especially WGNa) are likely due to imperfect washing of the fibers.

The experiments with the basalt and carbon rovings show that CFs are more resistant to both WGNa and WGK than BFs. So, they will probably also be more suitable for the production of geopolymer composites.

\subsection{Change of mechanical properties of fibers after 2, 6 weeks and 3 months}

Table 2 shows the average maximum strength values (10 measurements) for the investigated fibers after 2, 6 weeks and three months. Ten maximum strength measurements were made for each group of samples.

Table 2 Average values of maximum strength of CFs and BFs and their standard deviations [N]

\begin{tabular}{ccccccccccc}
\hline & \multicolumn{1}{c}{ CFs } & \multicolumn{7}{c}{ BFs } \\
\hline Time & $\begin{array}{c}\text { ref. } \\
\text { sample } \\
\end{array}$ & DW & $\mathrm{Ca}(\mathrm{OH})_{2}$ & WGNa & WGK & $\begin{array}{c}\text { ref. } \\
\text { sample }\end{array}$ & DW & $\mathrm{Ca}(\mathrm{OH})_{2}$ & WGNa & WGK \\
\hline $299 \pm 25$ & & & & & $759 \pm 87$ & & & & \\
$2 \mathrm{w}$ & - & $617 \pm 96$ & $611 \pm 73$ & $777 \pm 54$ & $721 \pm 82$ & - & $478 \pm 85$ & $345 \pm 99$ & $231 \pm 78$ & $239 \pm 51$ \\
$6 \mathrm{w}$ & - & $529 \pm 31$ & $630 \pm 98$ & $793 \pm 34$ & $668 \pm 68$ & - & $404 \pm 64$ & $318 \pm 72$ & $35 \pm 25$ & $151 \pm 50$ \\
$3 \mathrm{~m}$ & - & $622 \pm 99$ & $693 \pm 61$ & $775 \pm 33$ & $719 \pm 53$ & - & $390 \pm 83$ & $346 \pm 73$ & - & $98 \pm 15$ \\
\hline
\end{tabular}

The carbon roving Tenax J STS40 48K (3200 tex) is a compact bundle of elementary carbon fibrils. The maximum strength of the carbon roving without the influence of chemical solutions was measured in the range of $662-745 \mathrm{~N}$. Due to the effect of the solutions, drying and subsequent handling during the sample preparation, the roving was loosened, and evaluation deviations were subsequently registered. In the case of the carbon roving, it is possible to state that the individual solutions do not have either a short or long-term effect (for example, after three months) on the mechanical properties of the carbon roving.

The basalt roving (2400 tex) is a bundle of elementary BFs; the bond strength of the bundle is lower than that of the carbon roving. The maximum strength of the basalt roving without the influence of chemical solutions was measured in the range of $539-861 \mathrm{~N}$. The effect of the chemical solutions, especially the different types 
of water glass, was clearly demonstrated in this type of fiber. In the case of WGNa, the fibers completely decomposed after three months and in the case of WGK the average value of the maximum strength decreased by $60 \%$ (see Table 2). The acidic environment damaged the BFs, which in the long run led to their complete decomposition.

\subsection{Shielding efficiency of electromagnetic radiation}

The prepared samples of the geopolymer composites consisted of CFs or BFs grids (size $16 \times 12$; $22 \times 22$; or $34 \times 34 \mathrm{~mm}$ ) and nanoparticles of $\mathrm{MgO}$ (concentration $0.0 ; 5.0 ; 7.5$ or $10 \%$ ) incorporated to the matrix. The shielding properties of electromagnetic radiation were first compared between a non-additive geopolymer composite and a composite with carbon and basalt grids with distinctive grid sizes (Figure 3).
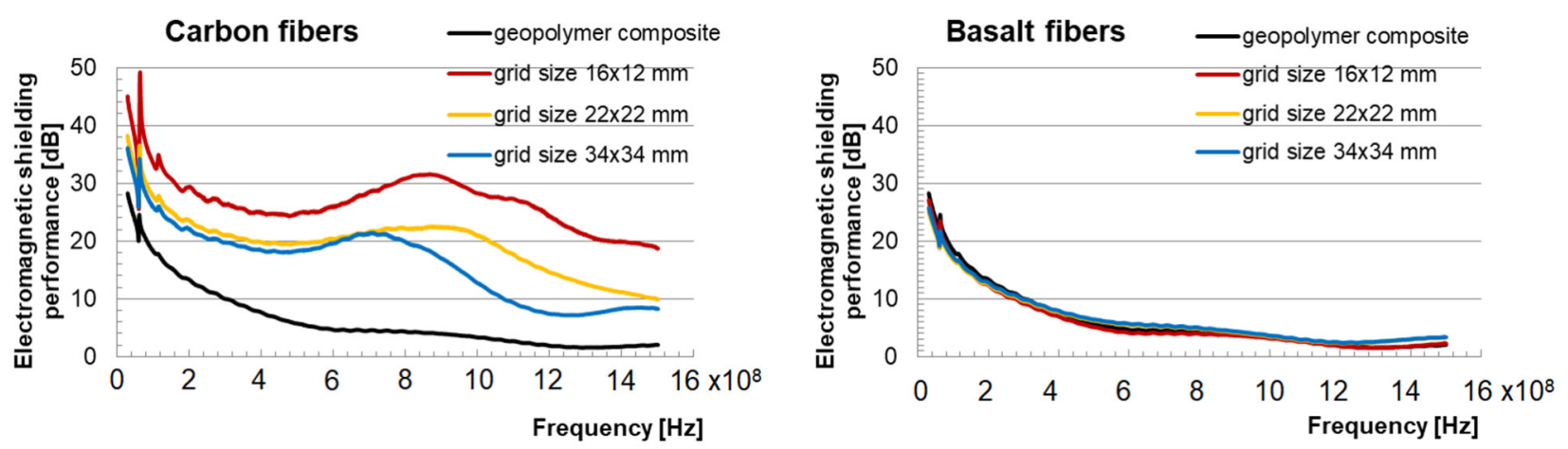

Figure 3 Geopolymer composites with carbon (left) or basalt (right) fiber grids (size $16 \times 12 ; 22 \times 22$ or $34 \times 34 \mathrm{~mm}$ ) incorporated into the geopolymer matrix

The geopolymer composite with no filling had a very low ability to shield the EM field especially at higher frequencies ( $\mathrm{SE}<5 \mathrm{~dB}$ for $\mathrm{f}>600 \mathrm{MHz}$ ). The electrically conductive carbon grid, added to the geopolymer composite, increased its EMS ability (Figure 3); the lower the dimensions of the meshes, the higher the EMS ability of the sample. This phenomenon can be explained by two facts: (a) the carbon mesh with the lower dimensions brings a more conductive component into the geopolymer composite, (b) the lower dimensions of the mesh do not allow penetration of the electromagnetic wave at higher wavelengths (lower frequency). A filling in the form of a BF grid does not provide any benefit to the composites with respect to their EMS ability, regardless of the dimensions of the grid, due to its very low electrical conductivity.

For the prepared composite samples, a carbon grid with a grid size of $16 \times 12 \mathrm{~mm}$ (Figure 4, left) and a basalt grid with a grid size of $16 \times 12 \mathrm{~mm}$ (Figure 4, right) were prepared, and MgO nanoparticles having a concentration of $0.0 ; 5.0 ; 7.5$ or $10 \%$ were added to the composites.
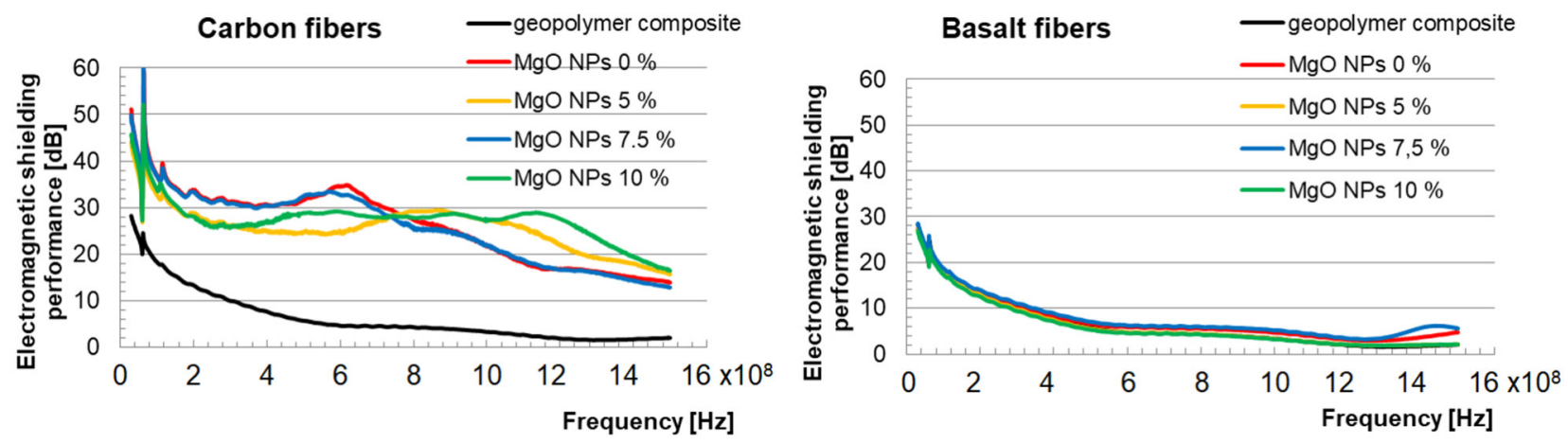

Figure 4 Geopolymer composites with carbon (left) or basalt (right) fibers grids (size $16 \times 12 \mathrm{~mm}$ ) and MgO NPs with concentrations of $0.0 ; 5.0 ; 7.5$ or $10 \%$ 
In both cases, the addition of MgO nanoparticles with different concentrations has almost no effect on the EMS ability (Figure 4). The variations in the SE of CFs filled by MgO NPs composites were probably caused by inconsistent preparation, or the inconsistent geometrical dimensions of the geopolymer samples.

\section{CONCLUSION}

The degradation capacity of $\mathrm{CF}$ and $\mathrm{BF}$ was determined by tensile strength testing; no significant differences were found in CFs. The mechanical properties of basalt rovings in water glass significantly decreased compared to fibers in water and in the $\mathrm{CaOH}_{2}$ solution, where the decrease in the mechanical properties is not significant. The decrease in the measured values of the mechanical properties of the fibers is partly caused by manipulation with the rovings (soaking, drying, sample preparation for the tensile strength test).

The addition of a conductive component into the geopolymer composite can increase its electrical conductivity, which causes an increase in EMS ability. Pure geopolymer composites have a relatively low shielding ability ( $\mathrm{SE}<5 \mathrm{~dB}$ for $\mathrm{f}>600 \mathrm{MHz}$ ), which decreases with increasing frequency. In the case of the use of a carbon mesh with dimensions of $16 \times 12 \mathrm{~mm}, 22 \times 22 \mathrm{~mm}, 34 \times 34 \mathrm{~mm}$, the SE was $20 \mathrm{~dB}, 10 \mathrm{~dB}$ and $8 \mathrm{~dB}$, respectively at a frequency of $1.5 \mathrm{GHz}$, which means that a mesh with lower dimensions provides higher SE. It was further confirmed that the addition of BF and MgO NPs had no statistically significant effect on the EM shielding ability of the composites, which is probably due to their very low electrical conductivity.

\section{ACKNOWLEDGEMENTS}

The results of the project „Application of geopolymer composites as fire, AGK“, registration number VI20172019055, were obtained through the financial support of the Ministry of interior in the program "The Safety Research of the Czech Republic" 2015-2020 (BV III/1-VS).

\section{REFERENCES}

[1] MUNALLI, D., G. DIMITRAKIS, D. CHRONOPOULOS, S. GREEDY and A. LONG. Electromagnetic shielding effectiveness of carbon fibre reinforced composites. Composites Part B: Engineering [online]. 2019, 173, 106906. ISSN 13598368. Available from: https://doi.org/10.1016/j.compositesb.2019.106906.

[2] SINGH, Ashish Kumar, Andrei SHISHKIN, Tarmo KOPPEL and Nikhil GUPTA. A review of porous lightweight composite materials for electromagnetic interference shielding. Composites Part B: Engineering [online]. 2018, 149, 188-197. ISSN 13598368. Available from: https://doi.org/10.1016/j.compositesb.2018.05.027.

[3] CHUNG, D.D.L. and Asma A. EDDIB. Effect of fiber lay-up configuration on the electromagnetic interference shielding effectiveness of continuous carbon fiber polymer-matrix composite. Carbon [online]. 2019, 141, 685-691. ISSN 00086223. Available from: https://doi.org/10.1016/j.carbon.2018.09.081.

[4] PRASAD, Rishu, Abd El-razek MAHMOUD and S.K.S PARASHAR. Enhancement of electromagnetic shielding and piezoelectric properties of White Portland cement by hydration time. Construction and Building Materials [online]. 2019, 204, 20-27. ISSN 09500618. Available from: https://doi.org/10.1016/j.conbuildmat.2019.01.140.

[5] PROVIS, J. L. and J. S. J. van DEVENTER. Geopolymers: Structures, Processing, Properties and Industrial Applications. B.m.: Elsevier, 2009. ISBN 978-1-84569-638-2.

[6] PAYAKANITI, Panjasil, Supree PINITSOONTHORN, Prasit THONGBAI, Vittaya AMORNKITBAMRUNG and Prinya CHINDAPRASIRT. Effects of carbon fiber on mechanical and electrical properties of fly ash geopolymer composite. Materials Today: Proceedings. 2018, 5(6), 14017-14025. ISSN 22147853.

[7] MASI, Giulia, William D. A. RICKARD, Maria Chiara BIGNOZZI and Arie VAN RIESSEN. The effect of organic and inorganic fibres on the mechanical and thermal properties of aluminate activated geopolymers. Composites Part $B$ : Engineering [online]. 2015, 76, 218-228. ISSN 1359-8368. Available from: https://doi.org/10.1016/..compositesb.2015.02.023. 
[8] RANJBAR, Navid, Mehdi MEHRALI, Arash BEHNIA, Alireza JAVADI PORDSARI, Mohammad MEHRALI, U. Johnson ALENGARAM and Mohd Zamin JUMAAT. A Comprehensive Study of the Polypropylene Fiber Reinforced Fly Ash Based Geopolymer. PLOS ONE. 2016, 11(1), e0147546. ISSN 1932-6203.

[9] LE CHI, Hiep and Petr LOUDA. Experimental Investigation of Four-Point Flexural Behavior of Textile Reinforcement in Geopolymer Mortar. International Journal of Engineering and Technology [online]. 2019, 10-15. ISSN 17938236. Available from: https://doi.org/10.7763/IJET.2019.V11.1115.

[10] LE CHI, Hiep, Petr LOUDA, Aravin PERIYASAMY, Totka BAKALOVA and Vladimir KOVACIC. Flexural Behavior of Carbon Textile-Reinforced Geopolymer Composite Thin Plate. Fibers. 2018, 6(4), 87. ISSN 2079-6439.

[11] LE CHI, Hiep, Petr LOUDA, Su LE VAN, Lukas VOLESKY, Vladimir KOVACIC and Totka BAKALOVA. Composite Performance Evaluation of Basalt Textile-Reinforced Geopolymer Mortar. Fibers. 2019, 7(7), 63. ISSN 2079-6439. 